\title{
The Association of MMP-8 Genotypes with Pterygium
}

\author{
PEI-SHIN HU ${ }^{1 *}$, WEN-SHIN CHANG ${ }^{2 *}$, AN-KUO CHOU ${ }^{2,3^{*}}$, NING-YI HSIA ${ }^{2}$, \\ YI-WEN HUNG ${ }^{4}$, CHIA-WEN LIN ${ }^{2}$, CIN-WUN WU ${ }^{2}$, CHUNG-YU HUANG ${ }^{5}$, MENG-FENG WU ${ }^{5}$, \\ CHENG-HSI LIAO ${ }^{6}$, CHIA-WEN TSAI ${ }^{2}$, DA-TIAN BAU ${ }^{2,6,7}$ and CHI-LI GONG ${ }^{8}$ \\ ${ }^{1}$ Department of Ophthalmology, Changhua Christian Hospital, Changhua, Taiwan, R.O.C.; \\ ${ }^{2}$ Terry Fox Cancer Research Laboratory, China Medical University Hospital, Taichung, Taiwan, R.O.C.; \\ ${ }^{3}$ Department of Anesthesiology, China Medical University Hospital, Taichung, Taiwan, R.O.C.; \\ ${ }^{4}$ Department of Medicine Research, Taichung Veterans General Hospital, Taichung, Taiwan, R.O.C.; \\ ${ }^{5}$ Taoyuan Armed Forces General Hospital, Taoyuan, Taiwan, R.O.C.; \\ ${ }^{6}$ Graduate Institute of Biomedical Sciences, China Medical University, Taichung, Taiwan, R.O.C.; \\ ${ }^{7}$ Department of Bioinformatics and Medical Engineering, Asia University, Taichung, Taiwan, R.O.C.; \\ ${ }^{8}$ Department of Physiology, China Medical University, Taichung, Taiwan, R.O.C.
}

\begin{abstract}
Background/Aim: Pterygium is composed of proliferating fibrovascular tissue, and its formation and progression are closely related to the homeostasis of the extracellular microenvironment. However, few studies have examined the contribution of matrix metalloproteinases $(M M P)$ to either diagnostic or prognostic potential in pterygium. In this study, we investigated the contribution of a polymorphism in the promoter region of MMP-8 (-799C/T) and two non-synonymous polymorphisms (Val436Ala and Lys460Thr) to pterygium. Materials and Methods: In this study, 134 patients with pterygium and 268 non-cancer controls patients were collected and the MMP-8 -799C/T, Val436Ala and Lys460Thr polymorphic genotypes of each subject were examined by polymerase chain reactionrestriction fragment length polymorphism (PCR-RFLP). Results: The results showed that the three polymorphisms investigated were not significantly associated with risk of pterygium. In addition, the stratified analysis showed that there was no interaction between MMP-8 genotype with age or gender on pterygium risk determination. Conclusion:
\end{abstract}

This article is freely accessible online.

*These Authors contributed equally to this study.

Correspondence to: Da-Tian Bau, Chi-Li Gong and Chia-Wen Tsai, Terry Fox Cancer Research Laboratory, China Medical University Hospital, 2 Yuh-Der Road, Taichung, 404 Taiwan, R.O.C. Tel: +886 422053366 Ext. 5805, e-mail: datian@mail.cmuh.org.tw; artbau2@gmail.com

Key Words: Age, gender, genotype, MMP-8, polymorphism, pterygium, Taiwan.
Polymorphisms at MMP-8 -799C/T, Val436Ala and Lys460Thr may not mainly contribute to determining personal susceptibility to pterygium in the Taiwanese examined.

Pterygium is a formation of fibrous tissue consisting of highly vascularized epithelial and subepithelial tissue that proliferates excessively and with an abnormal shape on the cornea. From the viewpoint of epidemiology, several physical and biological factors are reported to be associated with the pathogenesis of pterygium, including heat, dust, and other particles in the atmosphere, and immunological mechanisms, and regulations involving extracellular matrix reorganization, growth factors, cytokines, apoptosis, and angiogenesis. In recent years, mounting evidence has demonstrated that genetic factors play a significant role in the development of pterygium (1-4).

Matrix metalloproteinases (MMPs), also known as matrixins, are the major protein family in charge of regulating the homeostasis of extracellular matrix components (5). The MMPs perform a wide function in regulating the cell proliferation, differentiation, apoptosis, invasion, migration, metastasis, angiogenesis and immune surveillance during carcinogenesis (6). In literature, more and more evidence has shown that functional polymorphisms of MMPs may determine the inter-individual differences of susceptibility to several types of cancer (7-13). However, the difficulty in collecting enough samples from pterygium patients retarded the investigation of the role of MMPs in pterygium and only several reports with a small size of pterygium samples provided evidence for MMPs' playing a critical role in the development and progression of pterygium. For instance, a pilot study examined the 
in vivo $32: 41-46(2018)$

Table I. Distribution of selected demographics of the 134 pterygium patients and the 268 non-pterygium controls.

\begin{tabular}{|c|c|c|c|c|c|c|c|}
\hline \multirow[t]{2}{*}{ Characteristics } & \multicolumn{3}{|c|}{ Controls $(n=268)$} & \multicolumn{3}{|c|}{ Patients $(n=134)$} & \multirow[b]{2}{*}{$p$-Value } \\
\hline & $\mathrm{n}$ & $\%$ & Mean (SD) & $\mathrm{n}$ & $\%$ & Mean (SD) & \\
\hline Age at onset (years old) & & & $64.3(6.0)$ & & & $64.4(7.0)$ & 0.9660 \\
\hline Gender & & & & & & 1.0000 & \\
\hline Male & 156 & $58.2 \%$ & & 78 & $58.2 \%$ & & \\
\hline Female & 112 & $41.8 \%$ & & 56 & $41.8 \%$ & & \\
\hline
\end{tabular}

aBased on Student's $t$-test; bbased on the Chi-square test; SD: standard deviation.

expression of transcripts and proteins of MMPs in cultured human pterygium head, body, subconjunctival fibroblasts, and normal corneal and conjunctival fibroblasts. The results showed that MMP-1 and MMP-3, but not MMP-2, TIMP-1, TIMP-2 or UPA, were highly expressed in pterygium head, body and subconjunctival fibroblasts (14). Although Schellini and his colleagues demonstrated that the expression of MMP-9 was similar among the tissues from normal Tenon's capsule and primary or recurrent pterygia (15), Yang has oppositely proposed that the expression of MMP-9 by pterygium fibroblasts is significantly increased after the progression of pterygium (16). One of the reasons to explain the inconsistency is that the clinical sample sizes in the two researchers were only 6 and 15, respectively. Thus, the roles of MMPs in pterygium are still controversial and waiting to be revealed using not only a larger collection of samples, but also from studying the genetic in addition to the transcriptional or translational levels.

MMP-8 is a collagen regulator $(17,18)$, and the differential regulation patterns of MMP-8 may lead to different progression of cancers and pterygium among people of different genetic backgrounds of $M M P-8$. As early as 2007 , MMP-8 C-799T genotypes were found to be associated with breast cancer risk (19) and the electrophoretic mobility shift assays revealed differences in nuclear protein binding to oligonucleotides representing the $-799 \mathrm{C} / \mathrm{T}$ genotypes (20). In addition, the promoter constructs containing the CT and TT genotypes at the $-799 \mathrm{C} / \mathrm{T}$ had a 3 -fold greater activity in chorion-like trophoblast cells compared to the constructs containing the $\mathrm{C}$ alleles (20). However, as mentioned above, the role of $M M P-8$ genotypes has never been examined in pterygium. The current study aimed at investigating the association of MMP-8 -799C/T, Val436Ala and Lys460Thr polymorphisms with the susceptibility of pterygium.

\section{Materials and Methods}

Patients and controls. The protocol of the current study was approved by the Institutional Review Board of Changhua Christian Hospital and written informed consent was obtained from one or both parents of all participants [Changhua Christian Hospital IRB numbers: 141208]. One hundred and thirty-four patients diagnosed with pterygium were recruited in this study from the Departments at Changhua Christian Hospital, Taichung, Taiwan, Republic of China. All of the clinical characteristics of these patients, including their histological details, were identified by expert surgeons. All pterygium patients voluntarily participated, completed a questionnaire, and provided peripheral blood samples. The inclusion criteria of pterygium patients were apex of pterygium invading the cornea for more than $1 \mathrm{~mm}$. Healthy volunteers aged 45 years or more without pterygium or any type of cancer were enrolled as the control group for further selection. There were 78 males and 56 females in the pterygium group (age range of 48 to 89 years with an average age of 64.4). Finally, 268 non-pterygium healthy participants were included in the study in order to match the population structure (double the number of cases and matched for their ages and genders) with our pterygium population. The overall agreement rate in the study was above $85 \%$. Selected recorded characteristics of the subjects in pterygium and non-pterygium control groups are summarized and compared in Table I.

Methods for determining MMP-8 genotypes. Genomic DNA extracted from the peripheral blood leukocytes of each participant was extracted, aliquoted and stored as previously described (21). The primers for MMP-8 -799C/T, Val436Ala and Lys460Thr polymorphisms were designed by our team as previously published $(22,23)$. Briefly, genotyping polymerase chain reaction (PCR) cycling conditions via My Cycler (Biorad, Hercules, CA, USA) for $M M P-8$ were: one cycle at $94^{\circ} \mathrm{C}$ for $5 \mathrm{~min} ; 35$ cycles of $94^{\circ} \mathrm{C}$ for $30 \mathrm{sec}, 57^{\circ} \mathrm{C}$ for $30 \mathrm{sec}$ and $72^{\circ} \mathrm{C}$ for $30 \mathrm{sec}$ and a final extension at $72^{\circ} \mathrm{C}$ for $10 \mathrm{~min}(22,23)$.

Statistical analysis. Typical Pearson's Chi-square test without Yates' correction or Fisher's exact test was used to compare the distribution of the $M M P-8$ genotypes between pterygium and nonpterygium control groups. The associations between the $M M P-8$ polymorphisms and pterygium risk were estimated by computing odds ratios (ORs) as well as their 95\% confidence intervals (CIs) from unconditional logistic regression analysis with the adjustment for possible confounding factors when needed.

\section{Results}

Basic characteristics compared between pterygium patients and non-pterygium control group. The frequency distributions 
Table II. Distribution of matrix metalloproteinase-8 (MMP-8) genotypic frequencies among the pterygium and the control subjects.

\begin{tabular}{|c|c|c|c|c|}
\hline & Cases $(\%)$ & Controls (\%) & Adjusted OR $(95 \% \mathrm{CI})^{\mathrm{a}}$ & $p$-Value \\
\hline \multicolumn{5}{|l|}{ C-799T } \\
\hline CC (wildtype) & $74(55.2)$ & $138(51.5)$ & 1.00 (reference) & \\
\hline $\mathrm{CT}$ & $48(35.8)$ & $102(38.1)$ & $0.83(0.61-1.27)$ & 0.5645 \\
\hline TT & $12(9.0)$ & $28(10.4)$ & $0.78(0.39-1.54)$ & 0.5484 \\
\hline $\mathrm{CT}+\mathrm{TT}$ & $60(44.8)$ & $130(48.5)$ & $0.83(0.59-1.31)$ & 0.4799 \\
\hline \multicolumn{5}{|l|}{$\begin{array}{l}p_{\text {trend }} \\
\text { Lys460Thr }\end{array}$} \\
\hline AA (wildtype) & $130(97.0)$ & 265 (98.9) & 1.00 (reference) & \\
\hline $\mathrm{AC}$ & $4(3.0)$ & $3(1.1)$ & $2.14(0.45-9.36)$ & 0.1776 \\
\hline $\mathrm{CC}$ & $0(0.0)$ & $0(0.0)$ & -- & \\
\hline \multicolumn{5}{|l|}{ Val436Ala } \\
\hline TT (wildtype) & $134(100.0)$ & $268(100.0)$ & 1.00 (reference) & \\
\hline $\mathrm{CT}$ & $0(0.0)$ & $0(0.0)$ & -- & \\
\hline $\mathrm{CC}$ & $0(0.0)$ & $0(0.0)$ & -- & \\
\hline
\end{tabular}

OR: Odds ratio; CI: confidence interval. 'Data adjusted with confounding factors including age and gender. 'Based on Chi-square test without Yates' correction or Fisher's exact test; ${ }^{*} p<0.05$.

of the age and gender for 134 pterygium patients and 268 non-pterygium healthy controls are summarized and compared in Table I. The percentage of males was $58.2 \%$. No difference was found between the two groups as for age and gender since we have matched them very well $(p>0.05)$ (Table I).

Association analysis of MMP-8 genotypes at $-799 C / T$, Val436Ala and Lys460Thr with pterygium risk. The distribution of genetic frequencies as for the MMP-8 polymorphisms for the pterygium patients and controls are presented and compared in Table II. First, there were noticeably no CT or CC genotypes at $M M P-8$ Val436Ala among either the cases or the controls (Table II, lowest part). That is to say, all the Taiwanese people investigated in this study had the MMP-8 Val436Ala TT genotype (Table II, lowest part). Second, the ORs with adjusting those possible confounding factors (age and gender) for the people carrying variant $\mathrm{CT}$ and TT genotypes at $M M P-8$ promoter C-799T were $0.83 \quad(95 \% \mathrm{CI}=0.61-1.27, p=0.5645)$ and 0.78 (95\%CI=0.39-1.54, $p=0.5484)$ respectively, compared to those carrying the CC wild-type genotype (Table II, upper part). The $p$-value for trend was not significant $(p=0.7574)$ (Table II). In the dominant model (CT plus TT versus $\mathrm{CC}$ ), the association between $M M P-8$ promoter $-799 \mathrm{C} / \mathrm{T}$ polymorphism and the risk for pterygium was still not statistically significant (adjusted $\mathrm{OR}=0.83$, 95\% CI $=0.59$ $1.31, p=0.4799$ ) (Table II, upper part). Last, a very small percentage of Taiwanese people carried the heterozygous variant $\mathrm{AC}$ genotype at $M M P-8$ Lys460Thr (3.0\% and $1.1 \%$ in pterygium and control groups, respectively) and no association was found between $M M P-8$ Lys460Thr AC genotypes and the risk for pterygium (adjusted $\mathrm{OR}=2.14$, 95\% CI=0.45-9.36, $p=0.1776$ ) (Table II, medium part).

Association of MMP-8 allelic frequencies at -799C/T, Val436Ala and Lys460Thr and pterygium risk. Consistent with the findings in Table II, there is no differential distribution of allelic frequencies between the pterygium and control groups as for the $M M P-8$ promoter C-799T or Lys460Thr (Table III, upper part). In detail, the adjusted OR for the subjects carrying the $\mathrm{T}$ allele at $M M P-8$ promoter $\mathrm{C}$ 799T was 0.85 (95\% $\mathrm{CI}=0.61-1.33, p=0.4398)$, compared to those carrying the $\mathrm{C}$ wild-type allele (Table III, upper part). As for the allelic frequencies at $M M P-8$ Val436Ala and Lys460Thr polymorphic sites, there was no association between their genotypes and increased risk of pterygium (Table III, medium and lower parts).

\section{Discussion}

MMPs play an important role in the homeostasis of extracellular matrix components, and any imbalance of the extracellular microenvironment is related to the initiation and progression of cancer. For instance, Yang and his colleagues detected the mRNA expression levels and protein activities in various stages of surgically excised pterygium specimens and cultured pterygium fibroblasts. In that report, they also investigated normal conjunctiva specimens and fibroblasts as controls for comparison. The results showed that the MMP2 and MMP-9 expression levels in pterygium tissues and fibroblasts were higher than those of normal tissues and fibroblasts and closely relevant to the progression of pterygium. Also, in early-stage pterygium tissues and 
Table III. Allelic frequencies for matrix metalloproteinase-8 (MMP-8) polymorphisms among the pterygium and control subjects.

\begin{tabular}{lcccc}
\hline $\begin{array}{l}\text { Polymorphic } \\
\text { Allele }\end{array}$ & $\begin{array}{c}\text { Cases (\%) } \\
\mathrm{N}=268\end{array}$ & $\begin{array}{c}\text { Controls (\%) } \\
\mathrm{N}=536\end{array}$ & $\begin{array}{c}\text { Adjusted OR } \\
(95 \% \mathrm{CI})^{\mathrm{a}}\end{array}$ & $p$-Value $^{\mathrm{b}}$ \\
\hline C-799T & & & & \\
Allele C & $196(73.1)$ & $378(70.5)$ & 1.00 (reference) & 0.4398 \\
Allele T & $72(26.9)$ & $158(29.5)$ & $0.85(0.61-1.33)$ & \\
Lys460Thr & & & & \\
Allele A & $264(98.5)$ & $533(99.4)$ & 1.00 (reference) & 0.1795 \\
Allele C & $4(1.5)$ & $3(0.6)$ & 2.63 (0.44-8.71) & \\
Val436Ala & & & & \\
Allele T & $268(100.0)$ & $536(100.0)$ & 1.00 (reference) & \\
Allele C & $0(0.0)$ & $0(0.0)$ & -- & \\
\hline
\end{tabular}

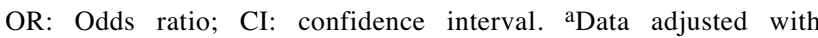
confounding factors including age and gender. ${ }^{b}$ Based on Chi-square test without Yates' correction or Fisher's exact test; ${ }^{*} p<0.05$.

cultured fibroblasts, MMP-2 or MMP-9 was at low or undetectable levels, while in advanced-stage pterygium (pterygium head passed the papillary region), MMP-2 and MMP-9 could be obviously detected in pterygium tissues and fibroblasts (16). In addition, down-regulation of the expression levels of MMP-3 and MMP-13 was capable of suppression of the proliferation and migration of pterygium fibroblasts $(24,25)$. These findings support the idea that MMPs may play an important role in the progression of pterygium, and the genomic markers on MMPs can serve as valuable predictive biomarkers for the development or reoccurrence of pterygium. In the literature, the genotypes of SNPs at promoter region of many $M M P$ genes were found to be associated with the risk of several types of cancer (713). However, no paper has investigated the role of polymorphisms of $M M P s$ as risk factors for pterygium.

Mounting evidence supported the idea that MMP-8 may play a critical role in the development of cancer. First, MMP-8 was found to be highly expressed in Jurkat $\mathrm{T}$ leukemia cells, which was closely related to the suppression of invasiveness in T cells (26). Second, the mutant mice deficient in $M M P-8$ were more susceptible to develop skin cancer $(27,28)$. From the viewpoint of a genomic study, some positive epidemiological findings reported that genotypes of promoter region of other MMPs such as MMP-1 and MMP-9, may serve as promising markers for the prediction of lung cancer susceptibility and prognosis (2931 ). From the molecular viewpoint, MMP-8 might increase cell adhesion by rearrangement of cytoskeleton actin, thus decreasing cell invasion (32). However, there were few epidemiological studies investigating the role of $M M P-8$ polymorphisms in the susceptibility of cancers (33). In 2008, the $\mathrm{G}$ variant allele at $M M P-8+17 \mathrm{C} / \mathrm{G}$ was found to be associated with a decreased risk of developing lung cancer (33). Thereafter in the present study, we firstly focused on the genotypes of $M M P-8$ polymorphisms and assessed whether there was an association between the genotypes of the promoter region of $M M P-8 \quad(-799 \mathrm{C} / \mathrm{T})$ and two nonsynonymous polymorphisms (Val436Ala and Lys460Thr) with pterygium risk. The results showed that no significant association was observed and our findings suggest that these three $M M P-8$ polymorphisms may not play a critical role in mediating susceptibility to pterygium (Tables II and III). Furthermore, when the analyses were stratified by age and gender, no significant association between these genotypes and pterygium risk was observed (data not shown). The negative findings of $M M P-8$ genotypes associated with pterygium, lung cancer (22) and oral cancer (23) hinted that MMP-8 may influence personal susceptibility to these diseases via other mechanisms such as regulation of proteinprotein interaction, but not simply from the level of genetic polymorphism.

There were several limitations of the study. First, the sample size is not as representative as those in common diseases such as cancers. The validation using larger sample sizes in multiple centers and populations is needed. Second, we did not perform the phenotypic measurements of MMP8 transcripts, protein level and activity among the patients and controls. Third, we did not stratify the pterygium population into subgroups according to their clinical characters, such as severity. There were several classification systems for pterygium. For instance, based on the relative translucency of the body, pterygium could be separated into atrophic, intermediate and fleshy types. It is expectable that the complete correlation of patient status, genotype and phenotype would be very helpful to understand the role of MMP-8 in the development of pterygium.

In conclusion, this is the first study to examine the association of genetic polymorphisms of $M M P-8$ with pterygium. Our results suggest that neither the genotypes of the promoter region C-799T nor nonsynonymous Val436Ala and Lys460Thr at MMP-8 was significantly conferring susceptibility to pterygium. Further studies elucidating the contribution of the genotypes of other members of MMPs to pterygium development will be helpful and the negative findings in this study need to be validated in other populations.

\section{Conflicts of Interest}

All the Authors declare no conflicts of interest.

\section{Acknowledgements}

The Authors are grateful to Hsin-Ting Li, Shiou-Ting Yen and Huai-Mei Hsu for their excellent technical assistance. All the participants in this study are appreciated. This study was supported 
mainly by Changhua Christian Hospital, Changhua, Taiwan R.O.C. to Dr. Hu (grant number: 141208) by Taoyuan Armed Forces General Hospital to Dr. Huang (ATTYGH-10628), and partially by research grant from Taiwan Ministry of Health and Welfare Clinical Trial and Research Center of Excellence (MOHW106-TDU-B-212-113004). The funders had no role in study design, data collection and analysis, decision to publish or preparation of the manuscript.

\section{References}

1 de PRJA, Dos Reis GM, KS ES, Rodrigues DA, Gomes MC, Martins JV, da Costa IR, Freitas GA and Moura KK: Analysis of the GSTM1-null polymorphism in patients with pterygium from Goiania, Goias Brazil. Genet Mol Res 14: 6173-6181, 2015.

2 Demurtas P, Orru G, Coni P, Minerba L, Corrias M, Sirigu P, Zucca I, Demurtas E, Maxia C, Piras F, Murtas D, Lai S and Perra MT: Association between the ACE insertion/deletion polymorphism and pterygium in Sardinian patients: a population based case-control study. BMJ Open 4: e005627, 2014.

3 Peng ML, Tsai YY, Tung JN, Chiang CC, Huang YC, Lee H and Cheng YW: Vascular endothelial growth factor gene polymorphism and protein expression in the pathogenesis of pterygium. Br J Ophthalmol 98: 556-561, 2014.

4 Rodrigues FW, Arruda JT, Silva RE and Moura KK: TP53 gene expression, codon 72 polymorphism and human papillomavirus DNA associated with pterygium. Genet Mol Res 7: 1251-1258, 2008.

5 de Souza AP, Trevilatto PC, Scarel-Caminaga RM, Brito RB and Line SR: MMP-1 promoter polymorphism: association with chronic periodontitis severity in a Brazilian population. J Clin Periodontol 30: 154-158, 2003.

6 Egeblad $\mathrm{M}$ and Werb $\mathrm{Z}$ : New functions for the matrix metalloproteinases in cancer progression. Nat Rev Cancer 2: 161-174, 2002.

7 Tsai CW, Chang WS, Gong CL, Shih LC, Chen LY, Lin EY, Li HT, Yen ST, Wu CN and Bau DT: Contribution of matrix metallopeptidase-1 genotypes, smoking, alcohol drinking and areca chewing to nasopharyngeal carcinoma susceptibility. Anticancer Res 36: 3335-3340, 2016

8 Sun KT, Tsai CW, Chang WS, Shih LC, Chen LY, Tsai MH, Ji HX, Hsiao CL, Liu YC, Li CY and Bau DT: The contribution of matrix metalloproteinase-1 genotype to oral cancer susceptibility in Taiwan. In Vivo 30: 439-444, 2016.

9 Lai CY, Chang WS, Hsieh YH, Hsu CM, Tsai CW, Chen AC, Wang $\mathrm{CH}$ and Bau DT: Association of tissue inhibitor of metalloproteinase-1 genotypes with lung cancer risk in Taiwan. Anticancer Res 36: 155-160, 2016.

10 Yu C, Zhou Y, Miao X, Xiong P, Tan W and Lin D: Functional haplotypes in the promoter of matrix metalloproteinase-2 predict risk of the occurrence and metastasis of esophageal cancer. Cancer Res 64: 7622-7628, 2004.

11 Hu Z, Huo X, Lu D, Qian J, Zhou J, Chen Y, Xu L, Ma H, Zhu J, Wei $Q$ and Shen H: Functional polymorphisms of matrix metalloproteinase- 9 are associated with risk of occurrence and metastasis of lung cancer. Clin Cancer Res 11: 5433-5439, 2005.

12 Chou AK, Hsiao CL, Shih TC, Wang HC, Tsai CW, Chang WS, Liu LC, Way TD, Chung JG and Bau DT: The contribution of matrix metalloproteinase-7 promoter genotypes in breast cancer in Taiwan. Anticancer Res 37: 4973-4977, 2017.
13 Liao CH, Chang WS, Hu PS, Wu HC, Hsu SW, Liu YF, Liu SP, Hung HS, Bau DT and Tsai CW: The contribution of MMP-7 promoter polymorphisms in renal cell carcinoma. In Vivo 31: 631-635, 2017

14 Li DQ, Lee SB, Gunja-Smith Z, Liu Y, Solomon A, Meller D and Tseng SC: Overexpression of collagenase (MMP-1) and stromelysin (MMP-3) by pterygium head fibroblasts. Arch Ophthalmol 119: 71-80, 2001.

15 Schellini SA, Hoyama E, Oliveira DE, Bacchi CE and Padovani CR: Matrix metalloproteinase-9 expression in pterygium. Arq Bras Oftalmol 69: 161-164, 2006.

16 Yang SF, Lin CY, Yang PY, Chao SC, Ye YZ and Hu DN: Increased expression of gelatinase (MMP-2 and MMP-9) in pterygia and pterygium fibroblasts with disease progression and activation of protein kinase C. Invest Ophthalmol Vis Sci 50: 4588-4596, 2009.

17 Hasty KA, Pourmotabbed TF, Goldberg GI, Thompson JP, Spinella DG, Stevens RM and Mainardi CL: Human neutrophil collagenase. A distinct gene product with homology to other matrix metalloproteinases. J Biol Chem 265: 11421-11424, 1990.

18 Devarajan P, Mookhtiar K, Van Wart H and Berliner N: Structure and expression of the cDNA encoding human neutrophil collagenase. Blood 77: 2731-2738, 1991.

19 Decock J, Long JR, Laxton RC, Shu XO, Hodgkinson C, Hendrickx W, Pearce EG, Gao YT, Pereira AC, Paridaens R, Zheng W and Ye S: Association of matrix metalloproteinase-8 gene variation with breast cancer prognosis. Cancer Res 67: 10214-10221, 2007.

20 Wang H, Parry S, Macones G, Sammel MD, Ferrand PE, Kuivaniemi H, Tromp G, Halder I, Shriver MD, Romero R and Strauss JF, 3rd: Functionally significant SNP MMP8 promoter haplotypes and preterm premature rupture of membranes (PPROM). Hum Mol Genet 13: 2659-2669, 2004.

21 Chuang CL, Wang CH, Hsu CH, Hsiao CL, Chen GL, Yen ST, Li HT, Chang WS, Tsai CW, Wang SC and Bau DT: Contribution of double-strand break repair gene nijmegen breakage syndrome 1 genotypes, gender difference and smoking status to Taiwanese lung cancer. Anticancer Res 37: 2417-2423, 2017.

22 Shen TC, Hsia TC, Chao CY, Chen WC, Chen CY, Chen WC, Lin YT, Hsiao CL, Chang WS, Tsai CW and Bau DT: The Contribution of MMP-8 promoter polymorphisms in lung cancer. Anticancer Res 37: 3563-3567, 2017.

23 Hung YW, Tsai CW, Wu CN, Shih LC, Chen YY, Liu YF, Hung HS, Shen MY, Chang WS and Bau DT: The contribution of matrix metalloproteinase- 8 promoter polymorphism to oral cancer susceptibility. In Vivo 31: 585-590, 2017.

24 Kim YH, Jung JC, Gum SI, Park SB, Ma JY, Kim YI, Lee KW and Park YJ: Inhibition of pterygium fibroblast migration and outgrowth by bevacizumab and cyclosporine A involves downregulation of matrix metalloproteinases-3 and -13. PLoS One 12: e0169675, 2017.

25 Tsai YY, Chiang CC, Yeh KT, Lee H and Cheng YW: Effect of TIMP-1 and MMP in pterygium invasion. Invest Ophthalmol Vis Sci 51: 3462-3467, 2010.

26 Kim MH, Albertsson P, Xue Y, Nannmark U, Kitson RP and Goldfarb RH: Expression of neutrophil collagenase (MMP-8) in Jurkat $\mathrm{T}$ leukemia cells and its role in invasion. Anticancer Res 21: 45-50, 2001. 
27 Balbin M, Fueyo A, Tester AM, Pendas AM, Pitiot AS, Astudillo A, Overall CM, Shapiro SD and Lopez-Otin C: Loss of collagenase-2 confers increased skin tumor susceptibility to male mice. Nat Genet 35: 252-257, 2003.

28 Montel V, Kleeman J, Agarwal D, Spinella D, Kawai K and Tarin D: Altered metastatic behavior of human breast cancer cells after experimental manipulation of matrix metalloproteinase 8 gene expression. Cancer Res 64: 1687-1694, 2004.

29 Liu B, Yi M, Tang Y, Liu Q, Qiu H, Zou Y, Peng P, Zhang L, $\mathrm{Hu} \mathrm{C}$ and Yuan X: MMP-1 promoter polymorphism is associated with risk of radiation-induced lung injury in lung cancer patients treated with radiotherapy. Oncotarget 7: 70175-70184, 2016.

30 Bayramoglu A, Gunes HV, Metintas M, Degirmenci I, Mutlu F and Alatas F: The association of MMP-9 enzyme activity, MMP9 C1562T polymorphism, and MMP-2 and -9 and TIMP-1, - 2, 3 , and -4 gene expression in lung cancer. Genet Test Mol Biomarkers 13: 671-678, 2009.

31 Liu L, Wu J, Wu C, Wang Y, Zhong R, Zhang X, Tan W, Nie S, Miao X and Lin D: A functional polymorphism (-1607 1G-->2G) in the matrix metalloproteinase-1 promoter is associated with development and progression of lung cancer. Cancer 117: 5172$5181,2011$.
32 Gutierrez-Fernandez A, Fueyo A, Folgueras AR, Garabaya C, Pennington CJ, Pilgrim S, Edwards DR, Holliday DL, Jones JL, Span PN, Sweep FC, Puente XS and Lopez-Otin C: Matrix metalloproteinase-8 functions as a metastasis suppressor through modulation of tumor cell adhesion and invasion. Cancer Res 68 : 2755-2763, 2008.

33 Gonzalez-Arriaga P, Lopez-Cima MF, Fernandez-Somoano A, Pascual T, Marron MG, Puente XS and Tardon A: Polymorphism $+17 \mathrm{C} / \mathrm{G}$ in matrix metalloprotease MMP8 decreases lung cancer risk. BMC Cancer 8: 378, 2008.

Received September 21, 2017

Revised October 14, 2017

Accepted October 17, 2017 